\title{
Analysis on Tourism in Heilongjiang Province Based on Climate Index
}

\section{Dandan Qi}

\author{
Institute of Business Economy, Harbin University of Commerce, Harbin 150028
}

\author{
Keywords: Heilongjiang Province, Tourism, Composite index, Climate
}

\begin{abstract}
Climate index refers to the use of quantitative indicators to reflect the status of the industry to reflect the changes in the industry boom. In this paper, we used the US Department of Commerce method to compile the tourism industry climate index of Heilongjiang Province, as a comprehensive evaluation of observing the fluctuation of tourism industry in Heilongjiang Province. Combined with the economic situation in Heilongjiang Province, we compiled the tourism industry in Heilongjiang Province climate index, in order to determine the overall industry fluctuations and trends, and to provide some reference for tourism industry in Heilongjiang Province for the formulation of policies and micro-tourism operators. The research indicates that the tourism industry in Heilongjiang province should develop to the group, carry out the internationalized management strategy, attach importance to the innovation ability of the staff, and cultivate its innovation spirit.
\end{abstract}

\section{Introduction}

The economic survey began in the late 19th century, the US Institute of Economic Research launched the diffusion index (DI) in 194 and the US National Bureau of Economic Research and the US Department of Commerce to develop a composite index (CI) in 1967, that are used to monitor economic fluctuations [1]. The CI can reflect the trend of the boom and the cycle of the boom, to make up for the lack of DI. In 1984, the Japan Economic Planning Agency (EPA) developed a composite index to measure the state of the Japanese economy [2]. After the 1990s, Stock and Wat son developed the SW Prosperity Index using the dynamic factor model [3]. In 2001, the Japan Economic Planning Agency also compiled a composite index [4].

China's research on the climate index mainly focuses on the analysis of China's macroeconomic cycle fluctuations or the specific situation of a particular industry boom and scientific forecast. In 1994, China's formal establishment of the business climate survey system, the current prosperity index analysis method is widely used in macroeconomics, financial securities, industry, agriculture, market and enterprise and other fields, rich research results for government departments to develop industry policy provides a basis. The study of the economy used in the field of tourism is relatively late. In 2006, Zhang Hui compiled the tourism prosperity index of Shichahai scenic area. Then Dai Bin and others studied the hotel, travel agency and other industries[5]. Bang Bang Media Center prepared a domestic tour destination climate index and outbound travel destination climate index[6].

At present, the research on tourism in Heilongjiang mainly focuses on the qualitative analysis, focusing on the problems existing in the tourism industry and solving the countermeasures, and also discusses from the management level. Through the analysis of relevant statistical data and the cyclical changes reflected in the development of tourism industry in Heilongjiang Province, the key indexes are extracted and the reference for the development of tourism in the province is provided. With the climate index can be analyzed and forecast the development trend of tourism in Heilongjiang Province, before the major economic changes, to prevent industry risks to provide technical and early warning.

\section{Research Methods and Model Selection}

In 1999, the tourism industry in Heilongjiang Province entered a period of rapid development, and the number of tourism-related industries increased significantly. Until 2003, after suffering from SARS hit, the tourism industry in Heilongjiang Province has begun to enter the track of industrial 
development. According to the data of tourism in Heilongjiang Province, the model is established to quantitatively and qualitatively analyze the fluctuation of the tourism industry, so as to predict the operation of the tourism industry and the business situation and future development trend of the tourism industry, and to revise it according to the actual situation of Heilongjiang Province, And thus the formation of the tourism industry in Heilongjiang Province in line with the actual prosperity index.

\section{The Process of Heilongjiang Tourism Industry Index Preparation}

We selected the selection of indicators to pull the network to collect indicators of the method, the impact of tourism in Heilongjiang tourism indicators of all factors are listed, a total of 39 effective indicators selected. Using the HDI historical diffusion index to initially calculate the benchmark date. Mainly using time difference correlation analysis to classify.

$x=\left\{x_{1}, x_{2} \ldots \ldots x_{n}\right\}, y=\left\{y_{1}, y_{2} \ldots \ldots y_{n}\right\}$ are selected indicators and benchmark indicators respectively, $\mathrm{r}$ is the time difference correlation coefficient, $\mathrm{y}_{t}$ is one of benchmark indicators $\left(\mathrm{y}_{1}\right.$, $\left.\mathrm{y}_{2} \ldots . . \mathrm{y}_{\mathrm{n}}\right) ; x_{t-l}$ is one of selected indicators $\left(\mathrm{x}_{1}, \mathrm{x}_{2} \ldots . . \mathrm{x}_{\mathrm{n}}\right) . x_{\text {is }}$ the average of the elements of the selected indicator. $\bar{y}$ is the average of the elements of the benchmark. $L$ is the maximum delay number; where 1 is the lead and lag. $n_{1}=2 L+1$ is the number of data after the alignment.

$$
r_{l}=\frac{\sum_{l=1}^{n_{l}}\left(x_{t-l}-\bar{x}\right)\left(y_{t}-\bar{y}\right)}{\sqrt{\sum_{l=1}^{n_{l}}\left(x_{t-l}-\bar{x}\right)^{2} \sum_{l=1}^{n_{l}}\left(y_{t}-\bar{y}\right)^{2}}} \quad l=0, \pm 1, \pm 2, \cdots, \pm L
$$

Using the time difference correlation analysis method, the K-L information method, the cluster analysis and the expert scoring method as the auxiliary, the selected indicators are divided into the first indicators, consistent indicators, lag indicators. The leading indicators can predict the overall economic peak and bottom of the overall economy. Using the time difference correlation analysis method, the K-L information method, the cluster analysis and the expert scoring method as the auxiliary, the selected indicators are divided into the first indicators, consistent indicators, lag indicators. The final index will be divided into leading, consistent and lagging three indicators group.

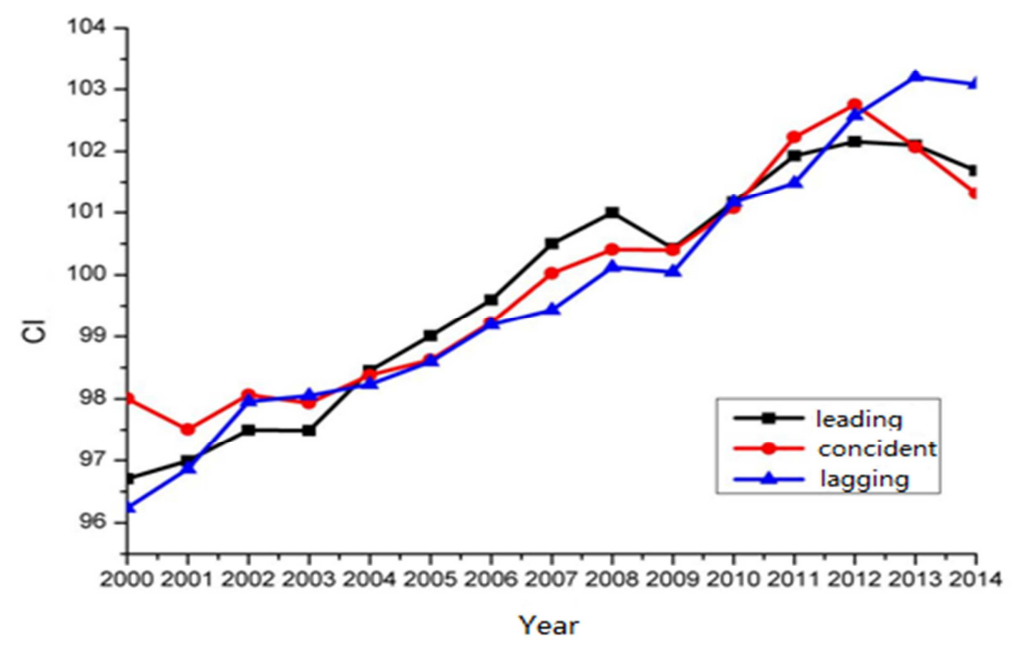

Fig.1 Heilongjiang Province tourism industry composite index 
From Figure 1, 2001 and 2003 Heilongjiang tourism operations into the bottom of the boom cycle, we believe that the 9/11 terrorist attacks and SARS will have an impact on the global tourism industry, but also led to a certain tourism in Heilongjiang Province influences. Large social disaster or security issues are the main factors affecting the tourism industry in Heilongjiang. From 2006 to 2007, the tourism industry in Heilongjiang Province is relatively in a relatively stable period of development, this period of China did not occur serious social finance, health, environmental and other issues. To the tourism industry in Heilongjiang Province in 2007 into the climate, the prosperity index reached 100 points, indicating that in a state of prosperity, showing steady and sustained growth trend. Although 2008 is a global economic turmoil, the tourism industry also had an impact, the 2008 Beijing Olympic Games held to promote the tourism industry, and there is no decline. Heilongjiang Province tourism industry there has been a growth trend, there has been a small peak. 2010 Shanghai World Expo is to promote the development of China's tourism industry, tourism in Heilongjiang Province is also in a good development environment. 2011 direct investment and investment in Heilongjiang Province more than 150 billion yuan. Provincial government and Provincial Tourism Bureau has increased support for tourism projects, supporting more than 200 tourism projects. In 2012, Heilongjiang to Russia "China Tourism Year" as an opportunity to vigorously promote the development of cultural tourism industry in Heilongjiang Province. The rapid development of tourism industry momentum, to achieve a new peak.

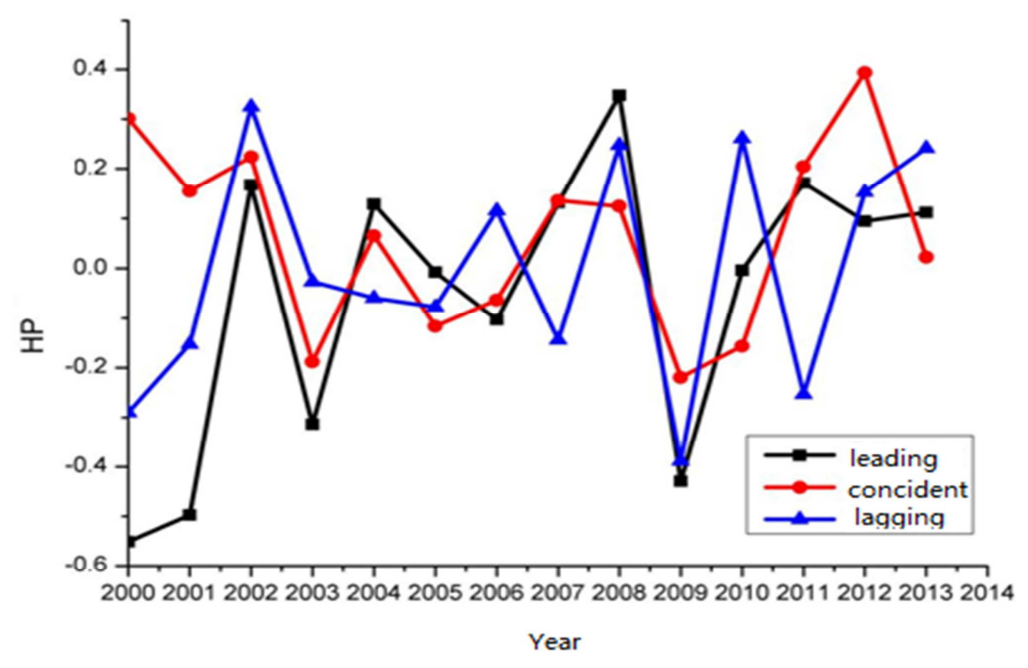

Fig.2 The leading, consistent and lagging H-P filter

According to Figure 2, the coherent index volatility chart can be seen, the first index 2006-2009 trend corresponding to the trend of 2010-2013, 2006 trend corresponding to the trend of 2010,2010 trend corresponding to the trend of 2013. We can see that there is a relatively stable relationship between the index lag, the first index is about 4 years ahead, there are four years ahead of the period. According to Figure 1 and Figure 2, 2012 - 2014 corresponding to the first index can be seen in the next few years, although the tourism market in Heilongjiang Province, a small contraction, but the overall tourism market will be in a state of mind. This also shows that we have previously established the climate index system is more reasonable. As the economic structure of the continuous adjustment, the prosperity index system is not static, and should be with the improvement of statistical data, and constantly adjust and amend. Some of the indicators of the weight of the relatively small, but its impact in the market activities can not be ignored, for such indicators we in the preparation of composite index, to increase its weight. In order to verify whether the index of increasing weight is in line with the actual market activity, we will build a mathematical model and verify its rationality to further refine the accuracy of the model of the composite index we have developed. The economic measure method of tourism in Heilongjiang 
Province provided in this paper has some reference significance for the monitoring of tourism tourism in the future.

\section{Conclusion}

In view of the problems in the tourism industry in Heilongjiang Province, we would like to make the following suggestions: First, we should strive to the development of the group. In order to enhance the competitive strength, in the province, the focus of the choice of several well-known, influential, good foundation of tourism enterprises focus on support. Name, build brand, enhance competitiveness, and ultimately in Heilongiiang Province to build tourism industry group. But also the introduction of other industries involved, such as to attract the transport industry in Heilongjiang Province, construction machinery, real estate and other enterprise groups into the tourism industry, these enterprises can also penetrate into the tourism industry through capital infiltration, tourism industry to provide development funds, expand business scope The Second, the expansion of international tourism business, to promote international business strategy. Encourage creative employees to provide training and learning opportunities, which is the necessary investment to enhance the overall competitiveness of the tourism industry.

\section{References}

[1] Burns, Arthur F.,and Wesley C.Mit chell, Measuring Business Cycles (New York: National Bureau of Economic Research ,1946.

[2] Shiskin ,J., et al.," T he X-11 Variant of the Census Method II Seasonal Adjustment Program," Technical Paper, US. Department of Commerce Bureau of the Census, 1967.

[3] James H.S tock, Mark W. Wat s on ,"A Simple Estimat or of Coin-tegrating Vectors in Higher Order Integrated Syst ems," Econo-met ri ca, Vol.61, No. 4 (Jul., 1993), pp. 783-820.

[4] Francis X.Diebold, Gl enn D. Rudebus ch, "Meas u ring Bus iness Cycles: A Modern Perspective," The Review of Economi cs and St at istics, Vol.78, No. 1 (Feb., 1996), pp.67-77.

[5] Zhang Hui. Urban Inbound Tourism Prosperity Index Construction - Taking Beijing as an Example [J]. Tourism Science. 2013 (12).

[6] Ni Xiaoning, Dai Bin. China tourism market prosperity index calculation and analysis [J]. Beijing Second Foreign Language Institute. 2004 (11). 